\title{
Influence of triethanolamine on cement pastes at early age of hydration
}

\author{
Marie Jachiet \\ PhD student, Centre des Matériaux des Mines d'Alès (C2MA), Ecole des \\ Mines d'Alès, Alès, France

\section{Nathalie Azéma} \\ Professor, Centre des Matériaux des Mines d'Alès (C2MA), Ecole des Mines \\ d'Alès, Alès, France (corresponding author: nathalie.azema@mines-ales.fr)

\section{Gwenn Le Saoût} \\ Professor, Centre des Matériaux des Mines d'Alès (C2MA), Ecole des Mines \\ d'Alès, Alès, France
}

Eric Garcia-Diaz

Professor, Centre des Matériaux des Mines d'Alès (C2MA), Ecole des Mines d'Alès, Alès, France

Vanessa Kocaba

Doctor, CHRYSO, Sermaises, France

\begin{abstract}
Accelerators (or activators) are commonly used as additives in cement to advance setting and/or hardening. Activation is often associated with the favoured hydration of particular cementitious phases, which can be induced by complexation mechanisms. However, the dispersion state of pastes with admixtures may also influence hydration rates. The aim of this paper is to highlight the correlation between mesostructural organisation and chemical reactivity of cement pastes with an additive. The affinity of triethanolamine (TEA), an activator molecule, with cement grains was assessed by measurement of total organic carbon. Moreover, the influence of the amine on the dispersion state, sedimentation kinetics and rheological behaviour was studied. Finally, X-ray diffraction, aluminium nuclear magnetic resonance spectroscopy and isothermal calorimetry were used in order to study the chemical reactivity of cement in the presence of the admixture. The combination of these granular and chemical characterisations helped to understand the mode of action of TEA.
\end{abstract}

\section{Introduction}

Accelerators (also called activators) are often used as additives in cement formulations to advance the setting and/or hardening of cementitious materials by accelerating cement hydration. They are therefore sometimes used in precast concrete to improve production rates or in ready-mixed concrete to limit hydration retardation in cold weather conditions. Among the different chemical species used as accelerators, ethanolamines such as triethanolamine (TEA) are efficient activator molecules. Many researchers have studied the use of TEA by looking at the chemical reactivity of cement by means of isothermal calorimetry, X-ray diffraction (XRD), thermogravimetric analysis or mechanical strength tests. TEA is usually considered to improve cement compressive strength and, depending on the dosage used, it can also act as a set retarder or accelerator (Aggoun et al., 2008; Aiad et al., 2003; Heren and Ölmez, 1996). Regarding the hydration kinetics, TEA slows down the hydration of the calcium silicate phase, but enhances calcium aluminate hydration and, more particularly, ettringite formation (Han et al., 2015; Huang and Shen, 2014; Ramachandran, 1976; Yang et al., 2017; Yaphary et al., 2017). Furthermore, TEA appears to form complexes with cations such as iron, aluminium or calcium, which might favour the dissolution/precipitation of some mineral phases in cement (Gartner and Myers, 1993; Heinz et al., 2010; Perez, 2002; Yilmaz et al., 1993; Zhang et al., 2016). Most of these studies were performed on cement pastes hydrated for relatively long periods (several months) and were focused on cement properties after setting.

In order to understand the mode of action of TEA, admixtured cement pastes also have to be investigated at an early hydration age. Along with chemical reactivity, the mesostructural organisation of the paste also has an impact on cement hydration (Costoya Fernandez, 2008). Mesostructural organisation can be defined as the physical arrangement of particles inside a suspension, at a scale ranging from micrometric (unit particle) to macroscopic (suspension) dimensions, including a description of the agglomeration state. During the induction period (the first hour or two of hydration), interactions between particles and an additive can modify the paste dispersion state and consequently influence its final structure (Berodier, 2015; Mikanovic and Jolicoeur, 2008). Direct and indirect techniques can be used to study the mesostructural organisation of cement paste in the presence of additives. In particular, dynamic and static approaches to study rheological (Aiad et al., 2003) and sedimentation behaviour (Autier et al., 2014; De Oliveira et al., 2003) can allow indirect assessment of concrete workability and setting. Modifications to admixtured cement properties are then often attributed to the ability of the additives to adsorb onto cement grains, thereby changing the particles' surface properties such as zeta potential (Elakneswaran et al., 2009; Mutin et al., 1998; Neubauer et al., 1998; Zingg et al., 2008).

The aim of the work reported in this paper was to study the influence of TEA on cement pastes by correlating mesostructural organisation and chemical reactivity. In this work, cement powder (without supplementary cementitious materials) was used to prepare pastes. Most characterisations were performed during the first hour of hydration. Nonadmixtured cement powder and paste were first characterised in various liquid media from a granular point of view. 
Table 1. Chemical, physical and granular characteristics of clinker powder

\begin{tabular}{|c|c|c|c|}
\hline Phase & XRD/Rietveld analysis: wt $\%^{a}$ & Element & $\mathrm{X}$-ray fluorescence: wt $\%$ \\
\hline Alite $\mathrm{M} 3\left((\mathrm{CaO})_{3} \cdot \mathrm{SiO}_{2}\right)$ & $58 \cdot 2$ & Sodium oxide $\left(\mathrm{Na}_{2} \mathrm{O}\right)$ & $0 \cdot 15$ \\
\hline Belite $\beta\left((\mathrm{CaO})_{2} \cdot \mathrm{SiO}_{2}\right)$ & $15 \cdot 8$ & Magnesium oxide (MgO) & $1 \cdot 69$ \\
\hline Belite $\alpha_{\mathrm{H}}^{\prime}\left((\mathrm{CaO})_{2} \cdot \mathrm{SiO}_{2}\right)$ & $6 \cdot 2$ & Aluminium oxide $\left(\mathrm{Al}_{2} \mathrm{O}_{3}\right)$ & $5 \cdot 33$ \\
\hline$(\mathrm{CaO})_{4} \cdot \mathrm{Al}_{2} \mathrm{O}_{3} \cdot \mathrm{Fe}_{2} \mathrm{O}_{3}$ & $12 \cdot 7$ & Silicon dioxide $\left(\mathrm{SiO}_{2}\right)$ & $21 \cdot 30$ \\
\hline$(\mathrm{CaO})_{3} \cdot \mathrm{Al}_{2} \mathrm{O}_{3}$ cubic & $4 \cdot 5$ & Phosphorus pentoxide $\left(\mathrm{P}_{2} \mathrm{O}_{5}\right)$ & $0 \cdot 27$ \\
\hline$(\mathrm{CaO})_{3} \cdot \mathrm{Al}_{2} \mathrm{O}_{3}$ orthorhombic & $1 \cdot 5$ & Sulfur trioxide $\left(\mathrm{SO}_{3}\right)$ & 0.86 \\
\hline Periclase (MgO) & $0 \cdot 6$ & Potassium oxide $\left(\mathrm{K}_{2} \mathrm{O}\right)$ & 0.67 \\
\hline \multirow[t]{4}{*}{ Aphthitalite $\left(\mathrm{KNaSO}_{4}\right)$} & 0.6 & Calcium oxide $(\mathrm{CaO})$ & $65 \cdot 30$ \\
\hline & & Titanium dioxide $\left(\mathrm{TiO}_{2}\right)$ & $0 \cdot 31$ \\
\hline & & Manganese oxide $(\mathrm{MnO})$ & 0.08 \\
\hline & & Ferric oxide $\left(\mathrm{Fe}_{2} \mathrm{O}_{3}\right)$ & $3 \cdot 23$ \\
\hline \multicolumn{2}{|c|}{ BET (Brunauer-Emmett-Teller) specific surface: $\mathrm{m}^{2} / \mathrm{q}$} & & \\
\hline \multicolumn{2}{|c|}{ Blaine specific surface: $\mathrm{m}^{2} / \mathrm{g}$} & & \\
\hline \multicolumn{4}{|c|}{ Surface area by granulometry: $\mathrm{m}^{2} / \mathrm{q}$} \\
\hline \multicolumn{2}{|c|}{ In ethanol } & & \\
\hline \multicolumn{2}{|l|}{ In deionised water } & & \\
\hline \multicolumn{2}{|l|}{ In air } & & \\
\hline \multicolumn{2}{|l|}{ Density: $\mathrm{g} / \mathrm{cm}^{3}$} & & \\
\hline \multicolumn{2}{|l|}{ Loss on ignition $\left(950^{\circ} \mathrm{C}\right)$ : wt\% } & & \\
\hline
\end{tabular}

aPerformed according to Le Saoût et al. (2011)

Scanning electron microscopy (SEM) and laser granulometry were used to identify different granular populations and their agglomerates and to determine the influence of the suspending fluid on the paste dispersion state. Following this, various concentrations of TEA were added to the cement paste. The adsorption ability of the molecule on cement grains was investigated by measurements of total organic carbon (TOC). The effect of TEA on mesostructural organisation was investigated by comparing the size distribution and physicochemical stability of pastes through optical microscopy, laser granulometry, multiple light scattering analysis (Turbiscan MA 2000) and rheological behaviour analysis. Finally, the influence of TEA on the chemical reactivity of the cement pastes was studied by analysing XRD patterns, aluminium nuclear magnetic resonance (NMR) spectra and measuring the heat flow evolution during hydration. The combination of mesostructural organisation and chemical reactivity allowed better comprehension of the mode of action of TEA regarding cement activation.

\section{Materials and methods}

\section{Materials}

The CEM I cement powder used in this study was prepared by mixing $95 \mathrm{wt} \%$ of clinker with $5 \mathrm{wt} \%$ gypsum $\left(\mathrm{CaSO}_{4} \cdot 2 \mathrm{H}_{2} \mathrm{O}\right)$. The clinker was ground in the laboratory without use of a grinding agent and thus the activator molecule added during paste preparation was the only additive present in the formulation. The chemical, physical and granular characteristics of the clinker are given in Table 1. Gypsum was added to the clinker in order to avoid cement flash set induced by early calcium aluminate phase hydration. The activator molecule TEA presents a dry mass extract of $86 \%$. It also contains around $10 \mathrm{wt} \%$ diethanolamine and $4 \mathrm{wt} \%$ water (Figure 1).

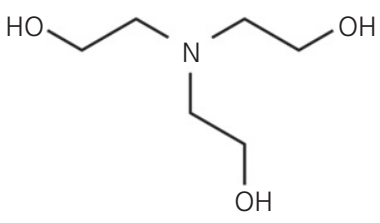

Figure 1. Molecular structure of TEA

\section{Methods}

\section{Paste preparation}

Cement pastes were prepared by mixing in two steps cement powder, TEA and deionised water at a water/cement ratio (w/c) of 0.4 . The amine dosage was varied between $0.05 \%$ and $0.60 \%$ dry mass extract with respect to cement. In practice, formulated accelerators are added to cement at a dosage varying in the range $1-5 \mathrm{wt} \%$, where amines present in the formulation represent $0 \cdot 02-0 \cdot 25 \mathrm{wt} \%$ with respect to cement. In this study, a larger concentration range was used, with especially high concentrations tested in order to exacerbate the action of TEA (Zhang et al., 2016). The mixing equipment consisted of a radial flow impeller blade fixed to a Stuart SS30 mixer and a stainless steel beaker of volume $50 \mathrm{ml}$. In the first step, the additive and water were weighed and mixed in the beaker. Cement was then added to this solution, corresponding to time zero of hydration. The suspension was stirred for $1 \mathrm{~min}$ at $500 \mathrm{rpm}$. Mixing was stopped for $1 \mathrm{~min}$ in order to scrape the blade and beaker. Finally, the suspension was stirred for a further minute at $1000 \mathrm{rpm}$.

For some experimental procedures (laser granulometry, optical microscopy and Turbiscan analysis), the pastes $(\mathrm{w} / \mathrm{c}=0 \cdot 4)$ 
Table 2. pH and ionic conductivity of cement pastes at different dilution rates in deionised water

\begin{tabular}{|lcrc|} 
Sample & $\begin{array}{c}\text { w/c } \\
\text { ratio }\end{array}$ & pH & $\begin{array}{c}\text { lonic } \\
\text { conductivity: } \\
\mathbf{m S} / \mathbf{c m}\end{array}$ \\
\hline Deionised water & - & 8.5 & 0.01 \\
Paste & 0.40 & $13 \cdot 0$ & 14.0 \\
Paste for Turbiscan analysis & 1.58 & 12.5 & 13.5 \\
Paste for laser granulometry & $10000-$ & 11.0 & 0.4 \\
$\quad$ measurement & 100000 & & \\
\hline
\end{tabular}

had to be diluted in order to adjust the solid volume fraction of the suspension according to the analytical technique used. Table 2 shows the $\mathrm{pH}$ and ionic conductivity of cement pastes prepared at various dilution rates in deionised water. Furthermore, different dilution liquids were used - ethanol, deionised water or a synthetic pore solution. The latter simulates the natural interstitial medium that surrounds cement particles in a paste. Its composition was adapted from the pore solution of a CEM I $42.5 \mathrm{~N}$ paste $(\mathrm{w} / \mathrm{c}=0.4)$ after $1 \mathrm{~h}$ of hydration (Lothenbach and Winnefeld, 2006): gypsum $=0 \cdot 8 \mathrm{~g} / \mathrm{l}$, potassium sulfate $\left(\mathrm{K}_{2} \mathrm{SO}_{4}\right)=19 \cdot 4 \mathrm{~g} / \mathrm{l}$, sodium hydroxide $(\mathrm{NaOH})=0.9 \mathrm{~g} / \mathrm{l}$ and potassium hydroxide $(\mathrm{KOH})=4 \cdot 3 \mathrm{~g} / \mathrm{l}$. Lower ion concentrations were chosen compared with experimental values of pore solutions in order to prevent calcium hydroxide $(\mathrm{CaOH})$ formation (saturation concentration around $20 \mathrm{mmol} / \mathrm{l}$ ).

\section{Granular characterisations}

Cement samples were analysed using an environmental scanning electron microscope (FEI Quanta 200 FEG). Powders were simply dispersed onto a SEM specimen stub and carbon deposited. In order to stop their hydration, cement pastes were immersed in liquid nitrogen for $5 \mathrm{~min}$ and freeze-dried overnight before analysis.

The particle size distributions (PSDs) of the cement powders and pastes were analysed using a Beckman Coulter LS 13320 laser granulometer. Measurement was based on static light scattering of monochromatic light $(750 \mathrm{~nm})$ by particles in suspension, with the deviation angle of the light correlated to particle diameter. This device is able to measure PSD in the range $17 \mathrm{~nm}$ to $2 \mathrm{~mm}$. For this purpose, an optical model specific to cement was defined for sample analysis with a refractive index of real part 1.75 and imaginary part $0 \cdot 1$ (Arvaniti et al., 2015). Measurements were performed in air or as suspensions diluted in ethanol, deionised water or synthetic pore solution (concentration $0 \cdot 01-0 \cdot 10 \mathrm{~g} / \mathrm{l}$ ) and lasted for $90 \mathrm{~s}$. During measurement, the suspensions were subjected to agitation (pump power 4). The results, represented in differential mode, gave the variation of volume percentage as a function of particle diameter. Depending on the particle size, some denominations are used to describe granular populations (Levine et al., 1991): particles of diameter $<1 \mu \mathrm{m}$ are called colloids, particles in the range $1-100 \mu \mathrm{m}$ are called supracolloids and particles of diameter $>100 \mu \mathrm{m}$ are referred to as settleable or granular particles.
The dispersion state of cement paste was studied using an optical microscope (Leitz Laborlux 12 Pol S) in transmission mode. After dilution of the paste in synthetic pore solution, a drop of suspension was placed on a glass slide and covered with a smaller glass slide. Due to capillary forces, the suspension spread out under the surface of the smaller glass slide. Zones containing different particle concentrations appeared and these zones were analysed in order to determine the mesostructural organisation of cement grains in the paste.

\section{Characterisation of additive adsorption}

The interactions between TEA and the cement grains were studied by TOC measurements. Measurements were performed on the pore solutions of admixtured cement pastes using an Elementar VarioTOC Cube. After $10 \mathrm{~min}$ of hydration, pore solutions were extracted by centrifugation (Hettich Rotina 380) at $10000 \mathrm{rpm}$ for $5 \mathrm{~min}$ and then filtered with a $0.45 \mu \mathrm{m}$ PTFE membrane filter. The device vaporises the solution at $850^{\circ} \mathrm{C}$ and measures the total quantity of carbon released with an infrared detector (detection of carbon dioxide $\left(\mathrm{CO}_{2}\right)$ band). As TEA contains six organic carbons, the quantity of the molecule present in the pore solution can be measured by means of TOC. Knowing the initial concentration of TEA in the paste, amine adsorption on cement grains can be calculated. Moreover, as cement paste without an additive already contains some carbon (inorganic carbon and pollutants), the signal of the pure paste was always subtracted from that of the admixtured pastes.

\section{Multiple light scattering analysis}

The physicochemical stability of the cement pastes was studied with a concentrated dispersion analyser (Formulaction Turbiscan MA 2000). Using this device, destabilisation phenomena such as settling behaviour can be followed over time. The principle of this technique relies on multiple light scattering. A monochromatic light source $(850 \mathrm{~nm})$ scans the entire analysis tube (external diameter of $15 \mathrm{~mm}$ and height $110 \mathrm{~mm}$ ). Transmitted and backscattered fluxes are detected at angles of $180^{\circ}$ and $45^{\circ}$ respectively from the incident beam. The intensity of both light fluxes is dependent on two main parameters, the solid volume fraction and the mean particle diameter (Mengual et al., 1999a, 1999b).

Backscattering and transmission profiles obtained by the Turbiscan device over time allow the detection of particle size change (agglomeration and dispersion) or particle migration (sedimentation kinetics). In this study, settling behaviour was studied in detail and decomposed into two main phenomena the evolution of a sedimentation front and supernatant clarification (Figure 2). Cement pastes prepared at $\mathrm{w} / \mathrm{c}=0.4$ were too concentrated for settling behaviour to be observed in a reasonable time. Thus, after the $3 \mathrm{~min}$ paste preparation period, the pastes were diluted with deionised water to obtain a suspension with $17 \%$ solid volume fraction $(w / c=1 \cdot 58)$. This suspension was gently stirred for $10 \mathrm{~min}$ using a magnetic stirrer. Then, $7 \mathrm{ml}$ of the suspension was placed in the analysis 

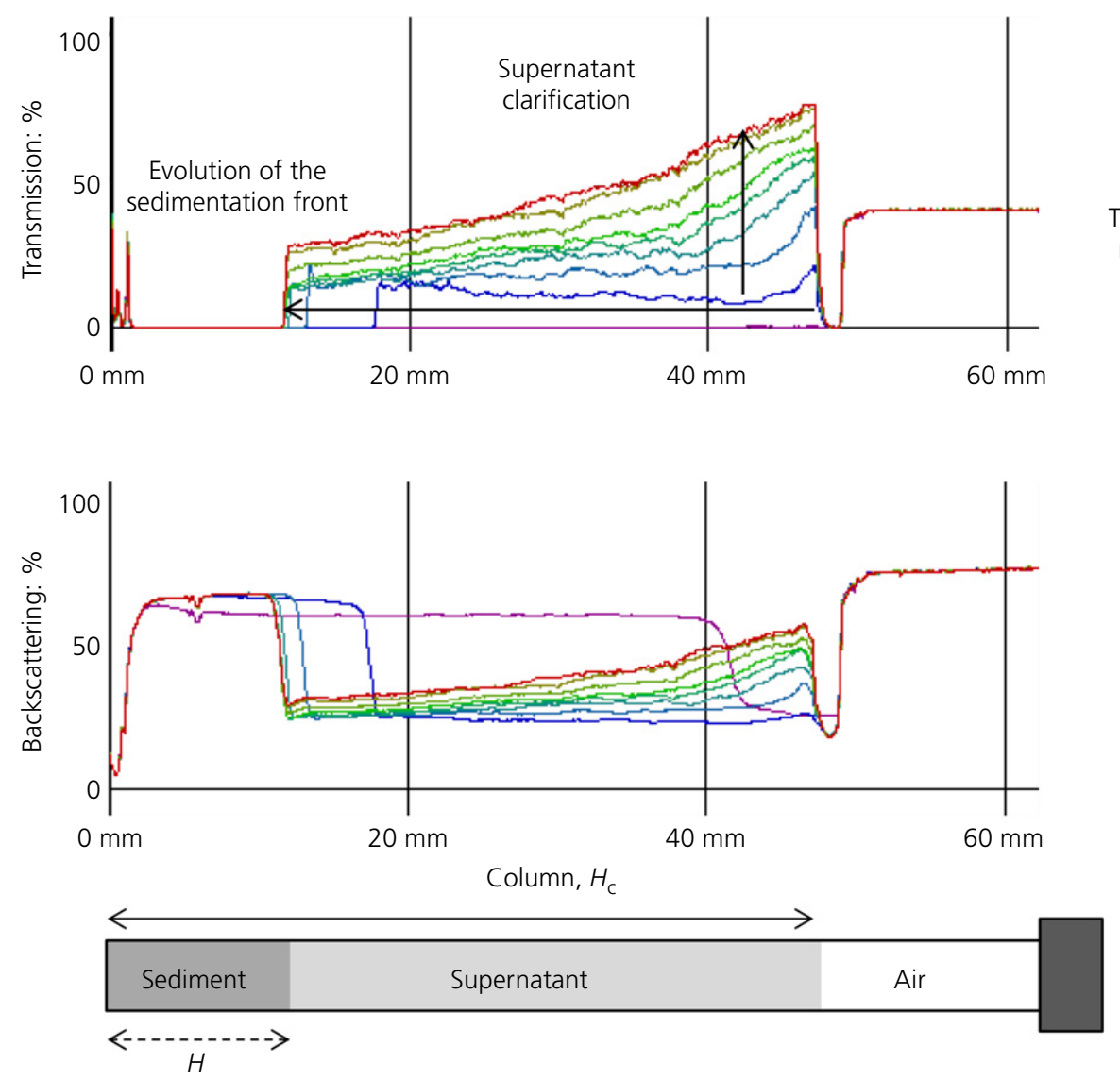

Figure 2. Example of the backscattering and transmission profiles of a suspension measured by Turbiscan MA 2000. A full-colour version of this figure can be found on the ICE Virtual Library (www.icevirtuallibrary.com)

tube. The analysis was conducted over $30 \mathrm{~min}$, with a profile measurement taken every $2 \mathrm{~min}$.

\section{Rheological behaviour}

The rheological behaviour of the cement pastes was characterised using a shear rheometer (TA Instruments AR 2000). A concentric cylinder geometry was chosen (bob diameter, $28 \mathrm{~mm}$; bob length, $41.98 \mathrm{~mm}$; cup diameter, $30 \mathrm{~mm}$; gap, $1 \mathrm{~mm}$ ). The temperature was fixed at $25^{\circ} \mathrm{C}$. Five minutes after the beginning of hydration, $100 \mathrm{~g}$ of cement paste $(\mathrm{w} / \mathrm{c}=0.4)$ was placed in the device for measurement. A pre-shear of $100 \mathrm{~s}^{-1}$ was first applied for $60 \mathrm{~s}$ to ensure homogeneity of the initial system. After a $30 \mathrm{~s}$ rest period, the shear rate was increased from zero to $200 \mathrm{~s}^{-1}$ over $1 \mathrm{~min}$ and then lowered back down zero over a further minute. For all the paste formulations, the rising and descending stress curves almost totally overlapped. The Bingham model was used to analyse the curves to determine the yield stress and the plastic Bingham viscosity on the descending ramp.

\section{Hydration kinetics}

An isothermal calorimeter (TA Instruments TAM Air) was used to follow the hydration kinetics of the cement pastes.
Pastes were first prepared by mixing at $w / c=0.4$ or 1.58 and then introduced to the device. The calorimeter measured the difference in heat flow between $5 \mathrm{~g}$ of cement paste and a reference (deionised water) at $25^{\circ} \mathrm{C}$. Cement hydration is a globally exothermic reaction and the heat flow curve can be divided into different stages that are characteristic of the hydration kinetics of ordinary Portland cement (Scrivener et al., 2015).

Some admixtured cement pastes were also studied by means of XRD and aluminium NMR spectroscopy. Cement hydration was stopped after $30 \mathrm{~min}$ of reaction by immersing the paste $(w / c=0.4$ or 1.58$)$ in isopropanol. After centrifugation and removal of the solvent by evaporation, the hydrated cement powder was recovered and then analysed with a Bruker D8 Advance diffractometer $(\mathrm{CuK} \alpha, \lambda=0 \cdot 154 \mathrm{~nm})$. The angle of the incident beam varied between $5^{\circ}$ and $70^{\circ}$, with a measurement duration of $30 \mathrm{~min}$. X'Pert High Score software was used to process the diffraction patterns and crystals were identified using the powder diffraction file database. Rietveld analysis yielded the mass fractions of the crystalline phases present in the cement. More specifically, the dissolution of gypsum present in the anhydrous cement powder and the precipitation of calcium aluminate hydrates (ettringite) formed at an early 
age of hydration were followed. Furthermore, solid ${ }^{27} \mathrm{Al}$ NMR spectra were recorded using an NMR spectrometer (Bruker Avance III $600(11.4 \mathrm{~T})$ ) at a frequency of $156.33 \mathrm{MHz}$ and a rotation magic angle spinning at $20 \mathrm{kHz}$ on a zirconia $\left(\mathrm{ZrO}_{2}\right)$ rotor of $3.2 \mathrm{~mm}$. A unique impulsion at $\pi / 12$ was applied with a recycle delay of $0.5 \mathrm{~s}$. Chemical shift was displayed relative to the shift of an aluminium chloride hexahydrate $\left(\mathrm{AlCl}_{3} \cdot 6 \mathrm{H}_{2} \mathrm{O}\right)$ solution $(1 \mathrm{~mol} / \mathrm{l})$ at $0.0 \mathrm{ppm}$.

\section{Results and discussion}

Granular characterisation of cement powder and paste without admixture

The granular characteristics of cement paste were compared with those of cement powder using different techniques as the protocol of paste preparation and suspending liquid might modify the granular state of the dispersed system studied.

According to the SEM micrographs (Figures 3(a) and 3(b)), the cement powder consisted of monomorphic angular particles due to the grinding process. The particle surfaces were quite smooth, which is consistent with the low specific surface of cement (below $1 \mathrm{~m}^{2} / \mathrm{g}$ according to BET theory). Moreover, the particle diameter was in the approximate range $200 \mathrm{~nm}$ to $150 \mu \mathrm{m}$, with a main mode close to $30 \mu \mathrm{m}$. Regarding mesostructural organisation, the cement particles formed different types of agglomerates. Colloidal particles tended to associate with other colloids or on the surface of supracolloid particles. Some examples of first- and second-order agglomerates are illustrated in Figure 3(a).

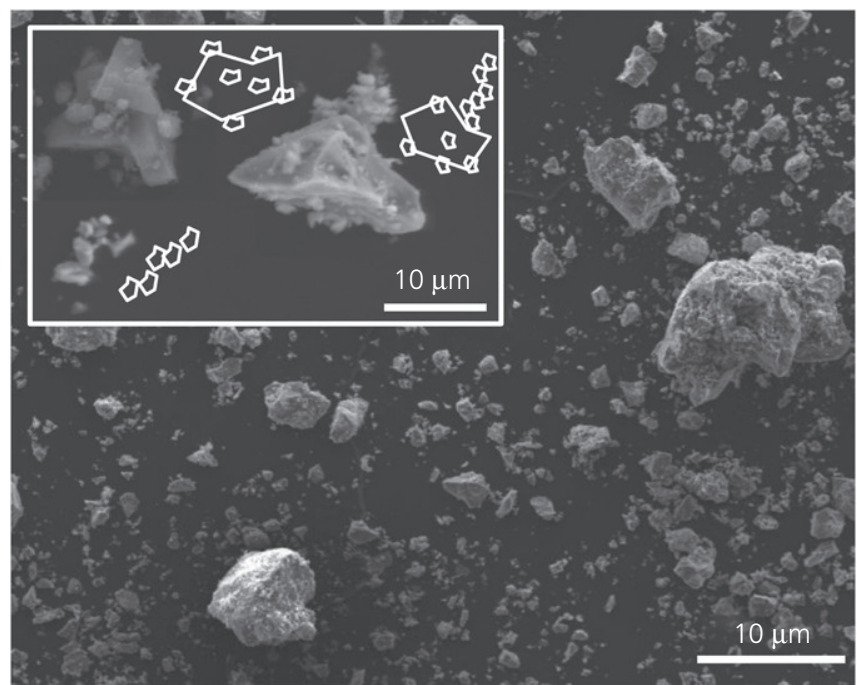

(a)

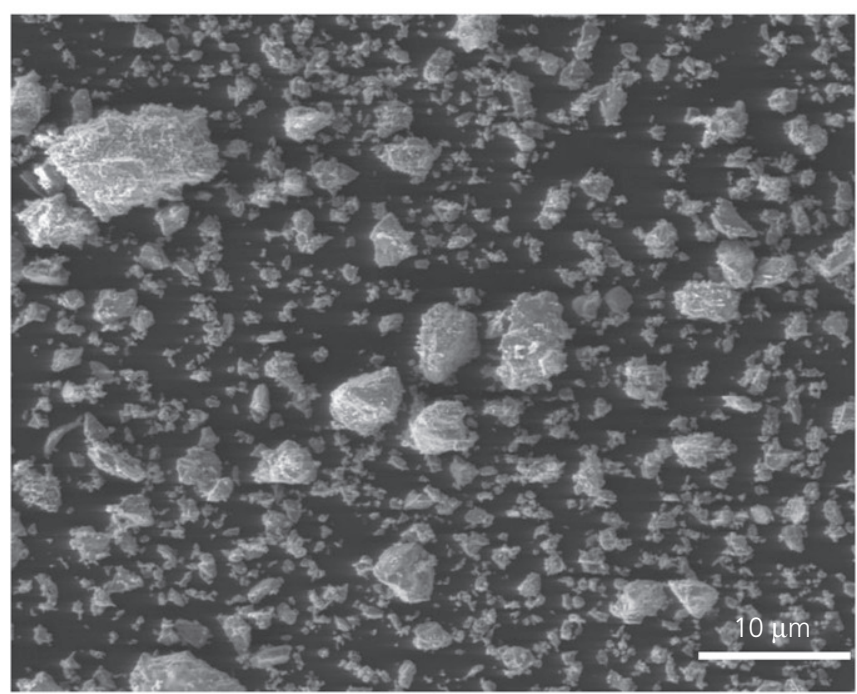

(c)

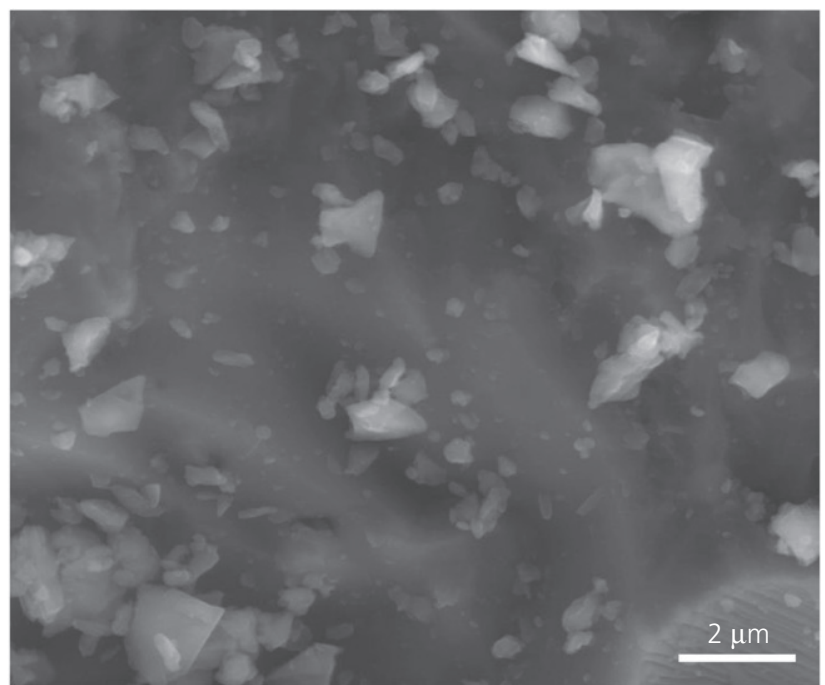

(b)

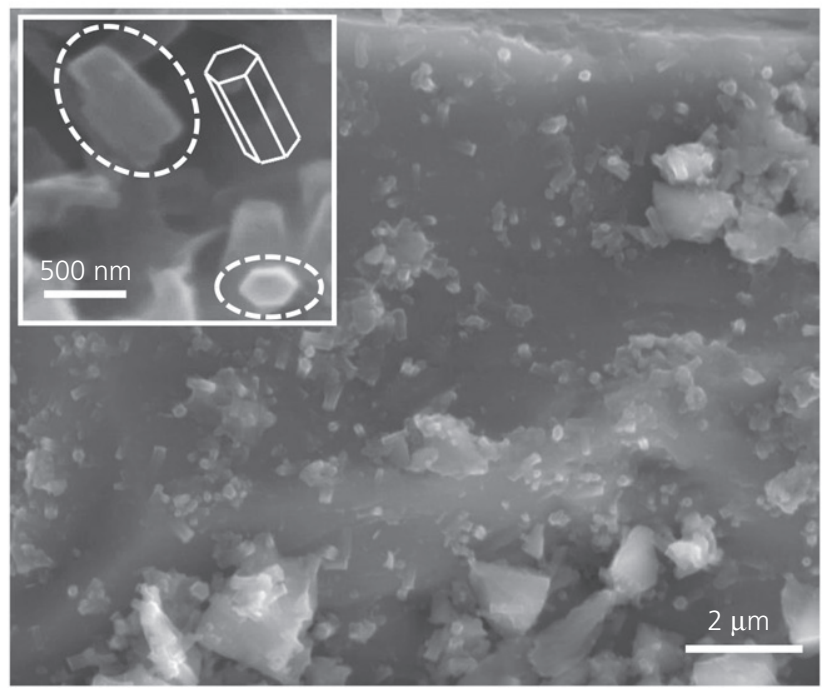

(d)

Figure 3. SEM micrographs of clinker powder ((a) and (b)) and cement paste ((c) and (d)) (freeze-dried after 10 min of hydration) 
After paste preparation, the particle characteristics were similar to those in the powder (Figures 3(c) and 3(d)). The size distribution, agglomerate structure and the surface of the grains remained almost unchanged after $10 \mathrm{~min}$ of hydration. However, a difference was observed due to cement hydration: small hexagonal needle-like hydrates $(0 \cdot 1-1 \mu \mathrm{m})$ had grown on the grain surface (Figure 3(d)), which can be attributed to the formation of ettringite (Shi et al., 2016; Xu et al., 2012).

The PSDs of the cement powder and paste were then analysed using laser granulometry and compared with the SEM observations. Different media were used for the measurements (air, ethanol, deionised water and synthetic pore solution) in order to verify the potential impact of the paste preparation protocol and choose the most appropriate liquid for further analysis (Figure 4).

The PSD of cement powder in air was in agreement with the SEM micrographs of the powder, with a maximum particle diameter around $100 \mu \mathrm{m}$. The mode around $1 \mu \mathrm{m}$ indicates the presence of a significant quantity of colloidal particles. Ethanol allows analysis of cement powder without the risk of hydration as ethanol is inert regarding cement reactivity. In comparison with the distribution in air, the maximum particle size remained the same, but fewer colloidal particles were detected. In fact, the liquid seems to favour the agglomeration of smaller particles on supracolloidal grains.

Likewise, for all the dilution liquids used, the supracolloidal PSDs of the cement paste $(1-100 \mu \mathrm{m})$ were in the same range as the powder, but two differences were noted: fine supracolloids $(1-15 \mu \mathrm{m})$ were less present in the deionised water sample and the maximum particle diameter was smaller for the synthetic pore solution (only $60 \mu \mathrm{m}$ ). The large particles (around $100 \mu \mathrm{m}$ ) detected in deionised water and in ethanol are probably agglomerates of supracolloids and not unit particles. Moreover, favoured cement grain hydration in the presence of deionised water compared with ethanol did not greatly change the granular characteristics of the paste. In fact, the small hydrates observed on the SEM micrographs seem to remain aggregated on the surface of supracolloidal particles and do not modify size distribution.

In conclusion, the cement powder and paste dispersed for up to $10 \mathrm{~min}$ in different liquid media presented similar granular characteristics according to the laser granulometry measurements. Changes in the PSD could have been expected due to shearing during paste preparation. In fact, using focused beam reflectance measurements, Han and Ferron (2016) observed that the size of weakly linked agglomerates increases at a high mixing speed. However, it should be pointed out that high dilution rates as well as agitation during measurement might hide differences in the dispersion states of the dilution liquids (Williams et al., 1999). For practical reasons and in order to obtain better control of the liquid medium, deionised water was mainly used as the dilution liquid for further analysis. In the presence of cement, deionised water rapidly acquires a composition similar to pore solution.

\section{Influence of TEA on the mesostructural organisation of cement pastes}

\section{TEA interaction with cement}

Measurements of TOC allowed the study of interactions between TEA and cement grains. As shown in Figure 5, the quantity of TEA measured in the pore solution of admixtured cement pastes appeared to be the same as that initially introduced into the formulation. Thus, at an early age of hydration, TEA interacts poorly with cement grains. This property has already been reported by other researchers using ionic chromatography measurements (Tritthart and Häussler, 2003). More particularly, TEA adsorption has been observed to increase

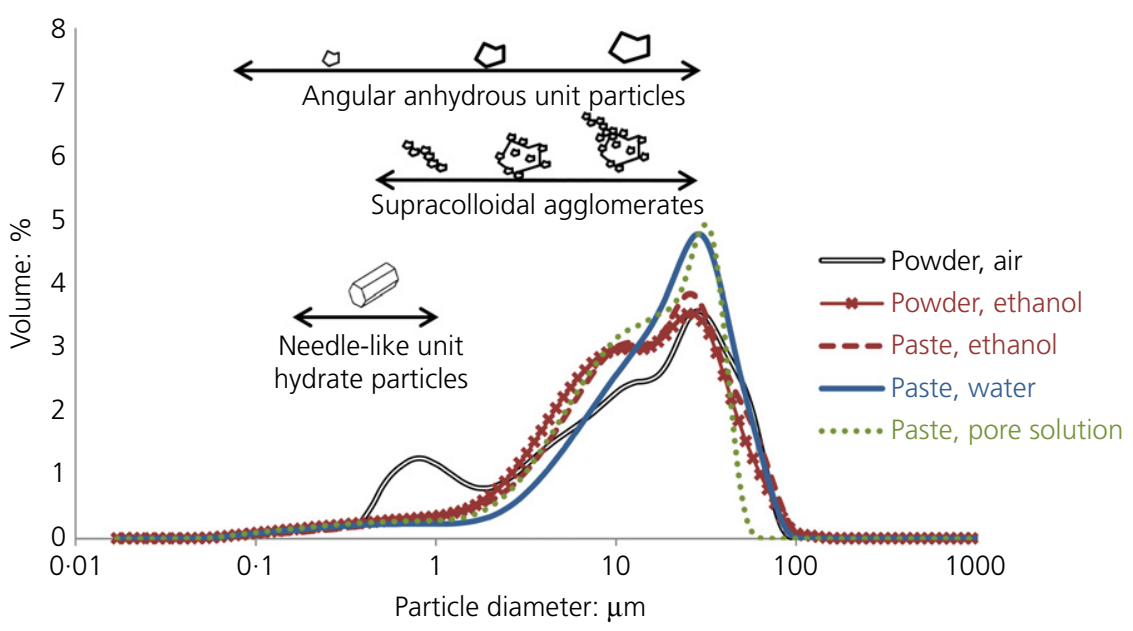

Figure 4. PSDs of cement powder and paste (after 10 min of hydration) in different media 
slowly over time, only reaching complete adsorption after more than $10 \mathrm{~h}$ corresponding to the sulfate depletion point (Gartner and Myers, 1993; Menek and Heren, 2000; Zhang et al., 2016).

Accordingly, TEA cannot have an electrostatic or steric effect as the molecule does not adsorb onto cement particles at an early age. However, it can act in solution, by inducing dispersive depletion forces or forming complexes. Depletion stabilisation has been reported for suspensions containing nonadsorbing polymers at high concentrations (Kim et al., 2015; Semenov and Shvets, 2015). TEA molecules might position on grain surfaces, forming a lubricating film and favouring particle dispersion. Moreover, TEA is known to favour the dissolution of some cations such as calcium, aluminium and iron by complexation mechanisms (Heinz et al., 2010; Yilmaz et al., 1993). The hydration of particular mineral phases can then be favoured, which induces particle aggregation. Both mechanisms will have an impact on the mesostructural organisation and chemical reactivity of cement pastes.

\section{Paste dispersion state}

The influence of TEA on the dispersion state was studied by observing diluted pastes under an optical microscope and by measuring the PSD with a laser granulometer. If TEA favours dispersion or agglomeration, the size distribution of cement particles should be modified and be visually observable (Flatt, 2001).

Cement pastes diluted in synthetic pore solution were observed $10 \mathrm{~min}$ after the beginning of hydration. A reference cement paste was compared to an admixtured paste, working at a high dosage of TEA $(0.60 \%)$ in order to exacerbate possible changes in the paste. According to Figure 6(a), the cement paste without TEA contained many supracolloidal and

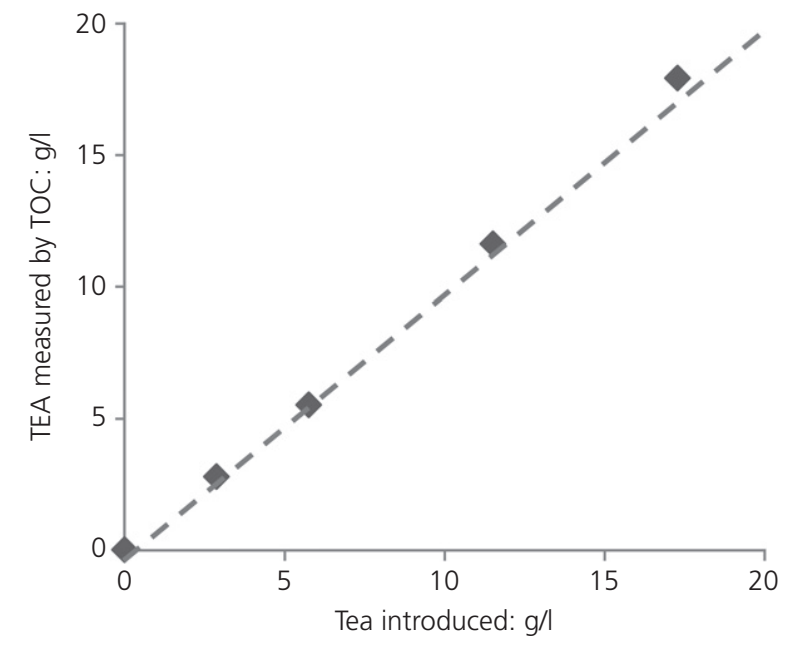

Figure 5. Evolution of TEA concentration measured by TOC in the pore solution after $10 \mathrm{~min}$ of hydration settleable agglomerates, whereas the admixtured paste (Figure 6(b)) contained many unit particles and almost no settleable agglomerates. TEA thus appears to favour the dispersion of particles inside the paste. As the viscosity of the TEA solution $\left(1.27 \mathrm{~Pa} . \mathrm{s}\right.$ at $\left.20^{\circ} \mathrm{C}\right)$ is equivalent to that of water, this phenomenon is induced by interparticle interactions and not by an evolution of pore solution characteristics. Since TEA does not adsorb on cement grains, it might act by inducing repulsive depletion forces in the pore solution.

Against all odds, regardless of the TEA dosage, the PSDs measured by laser granulometry in deionised water were the same as those of the non-admixtured cement paste. As microscope observations indicated a dispersant effect of TEA, a reduction in mean particle diameter was expected. It could be that laser granulometry might not be suitable for studying mesostructural organisation. In addition, the high sample dilution and agitation of the sample during measurement might have modified the paste dispersion state, thus obscuring any differences between samples.

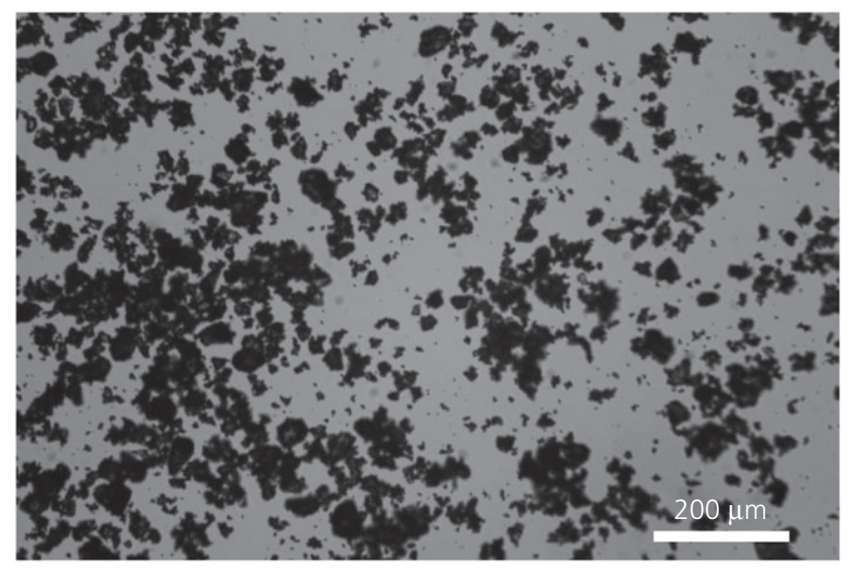

(a)

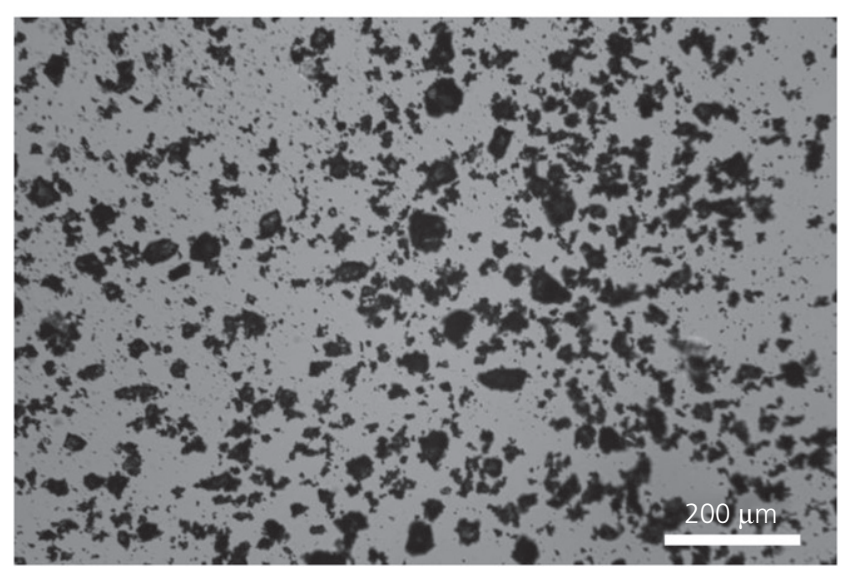

(b)

Figure 6. Micrographs of cement pastes prepared with (a) $0 \%$ TEA and (b) $0.60 \%$ TEA and diluted in synthetic pore solution after 10 min of hydration 


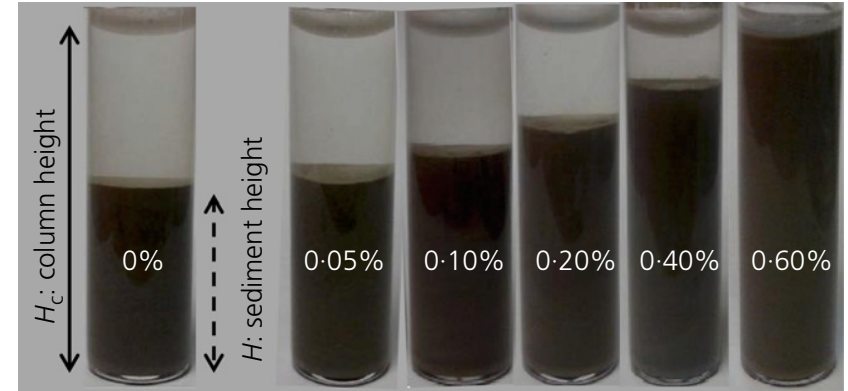

Figure 7. Visual appearance of sedimentation columns for different TEA dosages after 30 min of settling

\section{Settling behaviour}

The mesostructural organisation of the cement paste was studied indirectly by analysing the physicochemical stability of pastes diluted in water $(w / c=1.58)$ with the Turbiscan MA 2000 device. Visually, the presence of an interface between the settling suspension and clear supernatant revealed a hindered settling regime (Figure 7). Moreover, the sediment in formation was homogenous over its entire height, whereas the supernatant was clear and contained almost no particles. These characteristics along the sedimentation column are typical of a concentrated flocculated suspension where particles settle cooperatively and independently of their size (Neubauer et al., 1998). Thus, potential modifications of mesostructural organisation were analysed by following the evolution of the relative sediment height over time and calculating the associated sedimentation velocity.

With an increasing TEA concentration in the paste, the sedimentation velocity decreased, leading to the formation of a less compacted sediment after $30 \mathrm{~min}$ of settling (Figure 8). Between $0 \cdot 20 \%$ and $0 \cdot 40 \%$ TEA, the relative sediment height increased significantly, indicating modifications in cement hydration behaviour. For dosages higher than $0.60 \%$, no settling of the suspension was observed over the $30 \mathrm{~min}$ acquisition and the paste was entirely stabilised. The stabilisation of the paste with increasing TEA dosage could possibly be induced by two mechanisms. On the one hand, TEA might favour particle dispersion in the sedimentation column and thus slow down the settling; in fact, the dispersant effect of TEA was observed in diluted pastes (Figure 6). On the other hand, TEA addition might also favour hydrate formation, which would increase the solid volume fraction and fill in the sedimentation column. Strong and accelerated ettringite precipitation could stabilise the paste. The study of paste chemical reactivity could help differentiate these mechanisms.

\section{Rheological behaviour}

In order to study the dispersion state of admixtured pastes further, rheological measurements were performed on undiluted cement pastes $(w / c=0 \cdot 4)$. As the TEA dosage increased, the yield stress and plastic Bingham viscosity of the paste

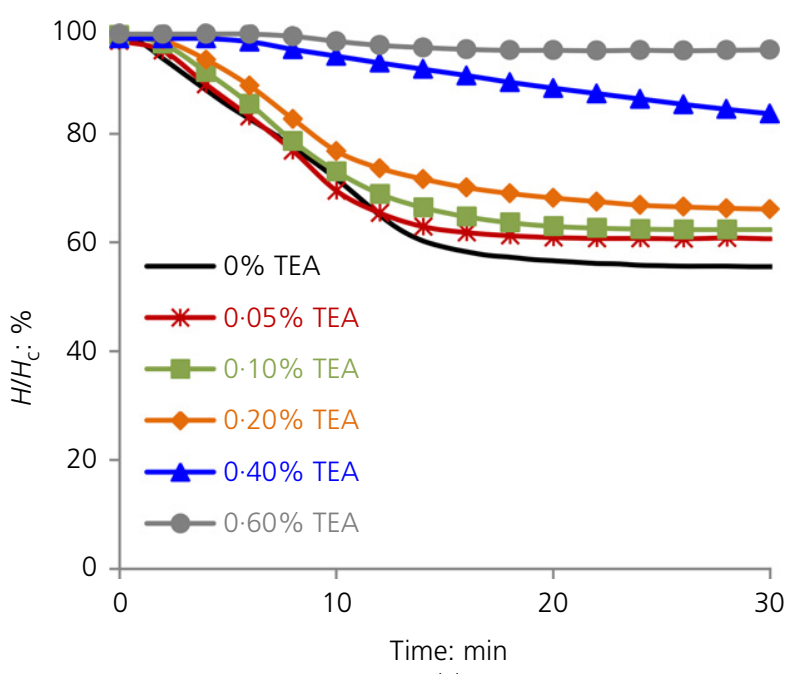

(a)

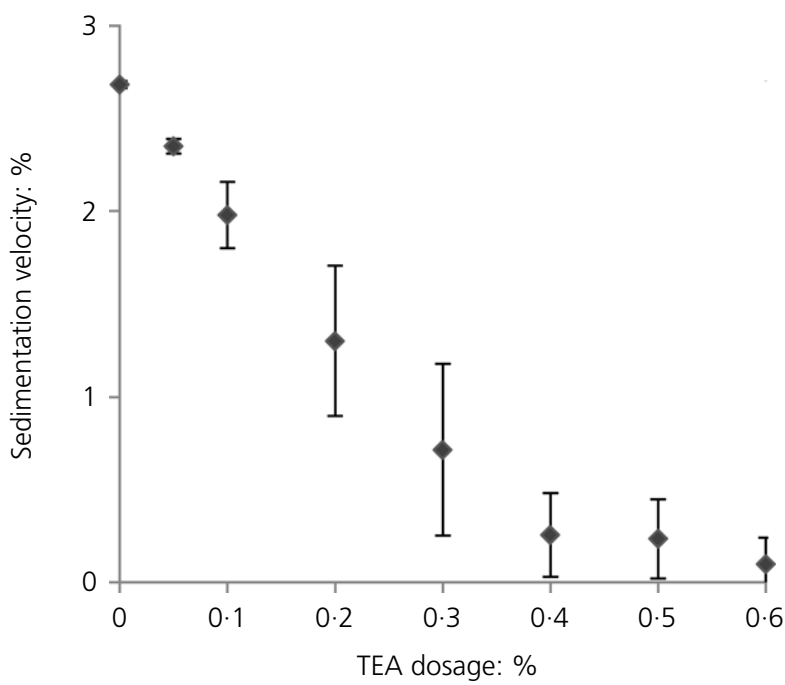

(b)

Figure 8. Evolution of (a) relative sediment height $\left(H / H_{c}\right)$ and (b) sedimentation velocity for pastes diluted in water with different TEA dosages

significantly increased, as shown in Figure 9. Thus, cement particles tend to agglomerate or aggregate in the presence of TEA. As the dispersant effect of TEA was highlighted through microscope observations, agglomeration of cement grains seems improbable. A decrease in plastic viscosity with amine addition would even have been expected. However, the precipitation of hydrates could lead to an increase in the solid volume fraction and, consequently, in viscosity.

It should be noted that the mesostructural organisation study has been performed on quite different systems. For microscope observation and physicochemical stability analysis, the paste was diluted and cement particles were only subjected to gravity. During rheological measurements, the paste was undiluted and subjected to shearing. In fact, the particle concentration and 


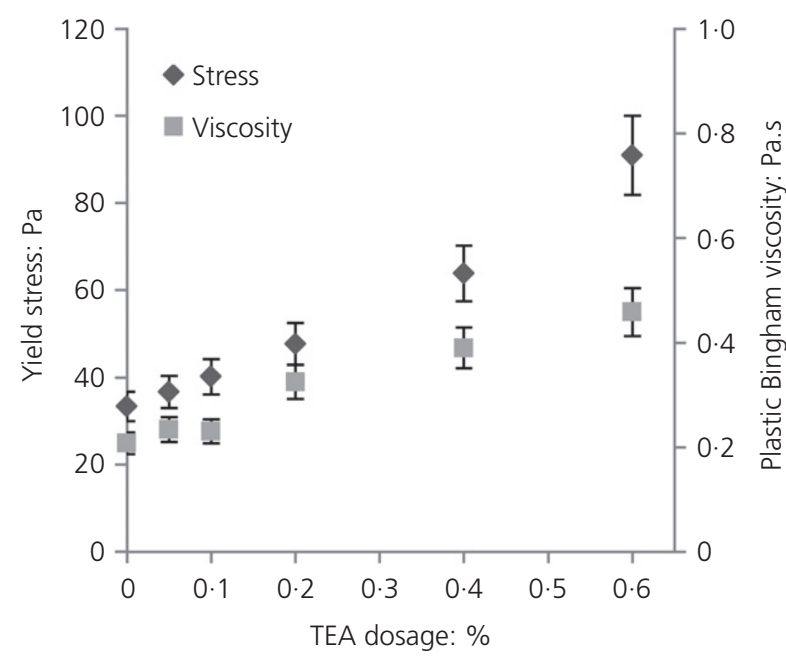

Figure 9. Evolution of cement yield stress and plastic Bingham viscosity for different TEA dosages

shearing rate have a strong influence on cement hydration kinetics. When the w/c ratio is low, interparticle distances are small and shearing between grains is increased (Berodier, 2015). The formation of nucleation sites can then be favoured, which leads to the acceleration of cement hydration. As TEA dosage increases, the precipitation of ettringite might be accelerated, leading to aggregation inside the paste and consequently an increase in viscosity. On the contrary, in diluted pastes, the chemical reactivity of the cement might be reduced as interparticle distances increase. Therefore, the impact of TEA on the dispersion state might prevail over hydrate precipitation. A study of cement chemical reactivity depending on the dilution rate could help to understand the differences in dispersion states in the presence of TEA.

\section{Influence of TEA on the chemical reactivity of admixtured cement pastes}

\section{Chemical reactivity at early age of hydration}

During the first hour of hydration, a strong exothermic reaction takes place, which is driven by cement dissolution and ettringite formation. XRD allowed measurement of the quantity of gypsum and ettringite present in the paste after $30 \mathrm{~min}$ of hydration. At a w/c ratio of $0 \cdot 4$, the addition of TEA led to accelerated consumption of gypsum and formation of ettringite (Figure 10(a)). In the XRD patterns (Figure 10(b)), the intensity of peaks associated with ettringite increased while the peak associated with gypsum at $11 \cdot 7^{\circ}$ totally disappeared when $0.8 \%$ TEA was added to the cement in comparison with the reference paste $(\mathrm{w} / \mathrm{c}=0 \cdot 4)$. Analysis of these samples by ${ }^{27} \mathrm{Al}$ NMR also confirmed the accelerated consumption of $\mathrm{C}_{3} \mathrm{~A}$ and the precipitation of ettringite with amine addition (Figure 10(c)). Indeed, the relative intensity associated with ettringite at $13.4 \mathrm{ppm}$ is higher for the sample containing $0.8 \%$
TEA than the reference (Le Saoût et al., 2006; Skibsted and Jakobsen, 1998). Thus, TEA appears to increase cement reactivity at an early age. The needle-like aluminate hydrates growing on the grain surfaces or in solution (Figure 3(d)) increase the solid volume fraction in the paste and could be responsible for the increase in plastic viscosity indicated by rheology measurement. This intense hydration acceleration might also hide the dispersant effect of TEA.

When the w/c ratio was increased from 0.4 to $1 \cdot 58$, gypsum dissolution and ettringite formation was slowed down. Thus, hydrate precipitation induced by TEA is less significant and therefore the dispersant effect of the additive could prevail. During settling, stabilisation of the sediment could be induced by both cement grain dispersion and an increase in the solid volume fraction due to ettringite precipitation.

To conclude, at an early age of hydration, TEA has a strong influence on both mesostructural organisation and chemical reactivity. Its action was illustrated and exacerbated by the use of different dilution rates. At a w/c ratio of $0 \cdot 4$, the acceleration of aluminate hydrates led to an increase in paste plastic viscosity and yield stress. Working on a diluted paste reduced the activator effect of TEA and proved its dispersing power.

\section{Hydration kinetics of cement pastes at $1 \mathrm{~d}$}

Over $90 \mathrm{~min}$ of hydration, the heat flow evolution of the cement was strongly affected by both TEA addition and an increase in w/c ratio (Figure 11). For the undiluted cement pastes $(w / c=0 \cdot 4$, Figure 11(a)), the addition of TEA accelerated calcium aluminate hydration. In fact, calcium silicate and aluminate peaks overlap at $10 \mathrm{~h}$ for TEA concentrations of $0 \cdot 05 \%$ and $0 \cdot 10 \%$. At $0 \cdot 20 \%$ TEA, the peaks still overlap and the induction period is also lengthened. For dosages higher than $0 \cdot 40 \%$, calcium aluminate hydration takes place during the first minutes of reaction (peak not visible) before calcium silicate hydration. As a consequence, the calcium aluminate hydrates that have developed might inhibit the formation of calcium silicate hydrates and retard the associated peak appearance until later than $90 \mathrm{~h}$ (Han et al., 2015; Ramachandran, 1976; Yang et al., 2017; Zhang et al., 2016).

At the higher w/c ratio (1·58, Figure $11(\mathrm{~b}))$, the same behaviour was observed. TEA addition accelerates calcium aluminate hydration and increases the heat flow intensity of this peak. At TEA concentrations above $0 \cdot 40 \%$, peak inversion takes place. However, calcium aluminate hydration is less accelerated and calcium silicate hydration is less retarded than in undiluted pastes. As pointed out in the discussion on paste sedimentation, paste dilution increases interparticle distances, which limits shearing between particles (Berodier, 2015). As a consequence, less nucleation sites are formed on the grain surfaces, which might slow down cement hydration from the first minutes of the reaction until $90 \mathrm{~h}$. Moreover, due to the paste dilution, ion concentrations in the pore solution are 


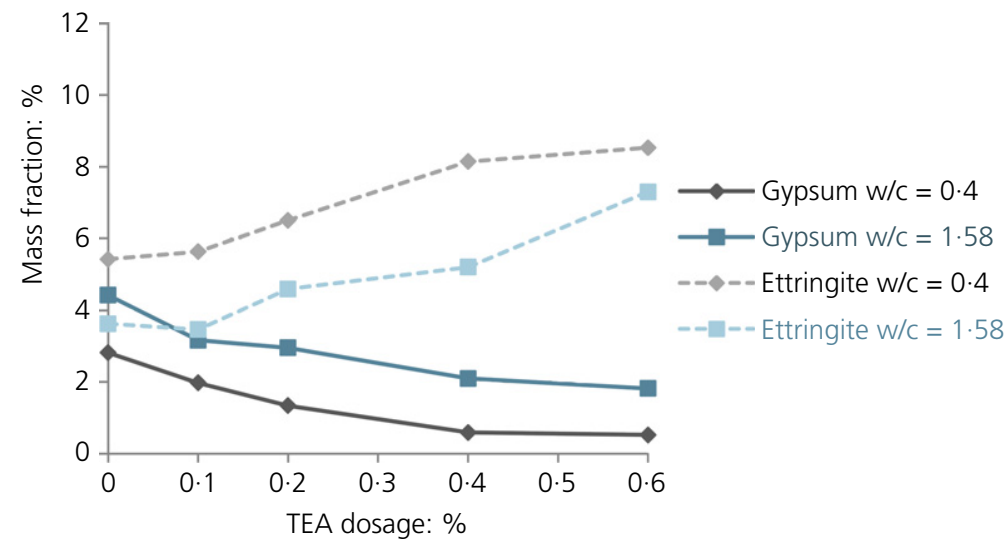

(a)

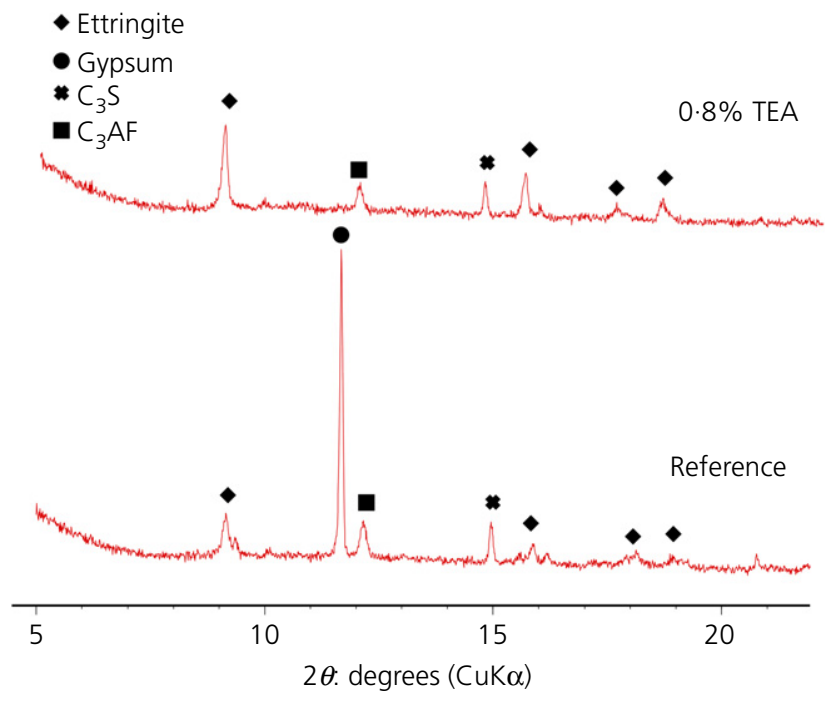

(b)

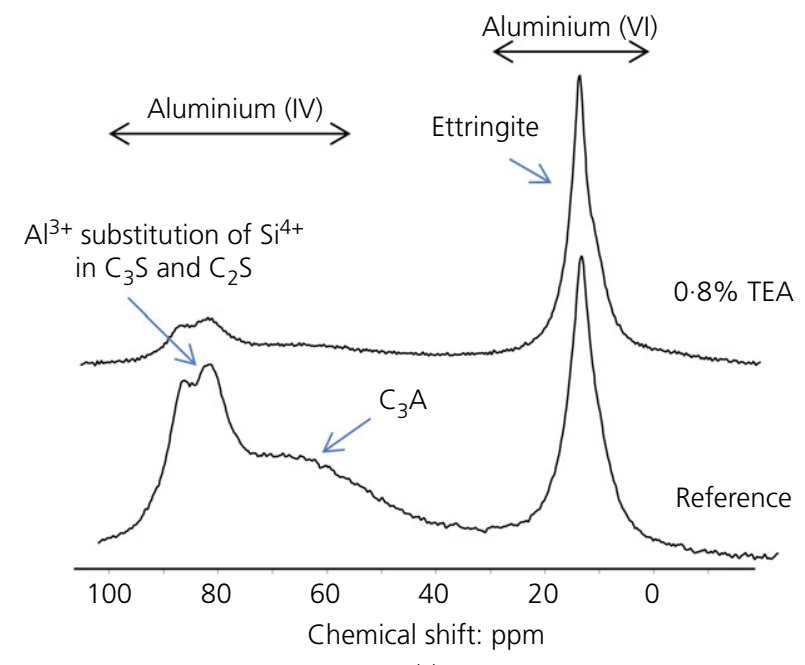

(c)

Figure 10. (a) Mass fraction of gypsum and ettringite measured by XRD after 30 min of hydration (w/C $=0.4$ and 1.58). (b) XRD pattern and $(c){ }^{27} \mathrm{Al}$ NMR spectrum of reference paste and paste with $0.8 \%$ TEA $(\mathrm{w} / \mathrm{c}=0.4)$ after $30 \mathrm{~min}$

modified. It might take more time for the chemical species (e.g. portlandite) to reach supersaturation and precipitate. Thus, the whole hydration kinetics could be slowed down.

It thus appears that TEA activates calcium aluminate hydration significantly. This outcome is in line with the earlyage behaviour and with other studies performed on the impact of TEA addition to cement (Ramachandran, 1976; Yaphary et al., 2017). This acceleration might be linked to the complexation ability of TEA. Indeed, some authors have noted the formation of complexes between TEA and ferric, aluminium or calcium ions (Heinz et al., 2010; Yilmaz et al., 1993; Zhang et al., 2016). In particular, during the first minutes of hydration, complexation of TEA with calcium ions from gypsum might favour the dissolution of this anhydrous phase. As a consequence, free sulfate ions liberated in the pore solution can react with the aluminate phase to form ettringite. This acceleration of the aluminate phase hydration at an early age might then continue at later ages, leading to an early appearance of the sulfate depletion point.

\section{Conclusions}

The effect of TEA, a common cement additive, was studied by correlating mesostructural organisation and chemical reactivity of admixtured cement pastes. First, different granular populations and agglomerate types were identified in the cement powder and paste using SEM and laser granulometry. In a second step, the impact of TEA on the mesostructural organisation of cement pastes was studied. TOC measurements showed that almost no amine was adsorbed on cement grains after $10 \mathrm{~min}$ of hydration. TEA probably has no electrostatic or steric effect, but might rather act in solution. Observation of diluted pastes under an optical microscope revealed that in the presence of TEA the dispersion of cement particles was more 


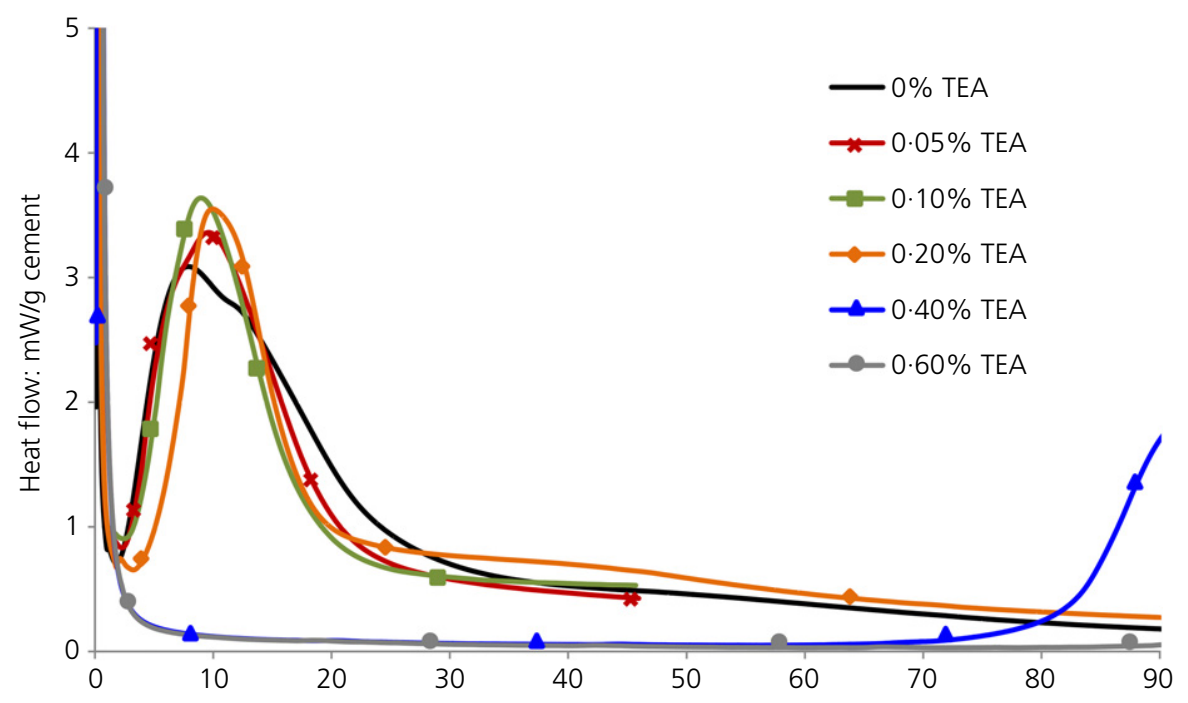

(a)

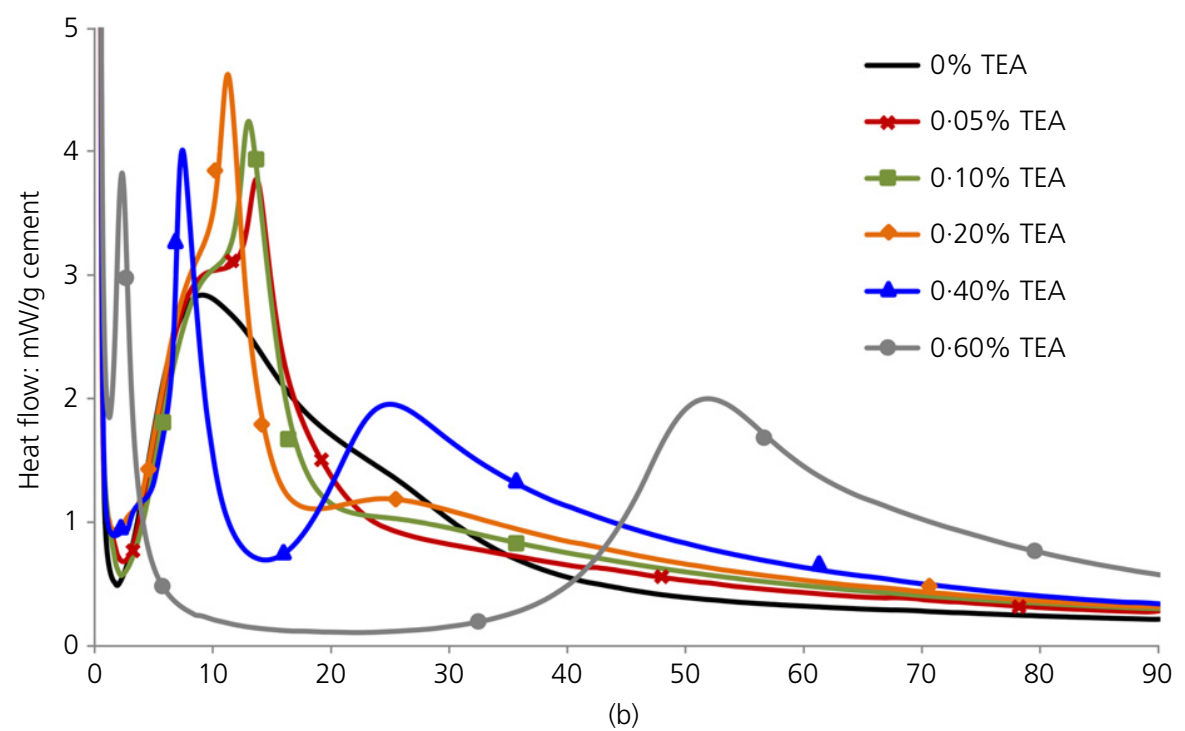

Time: $\mathrm{h}$

Figure 11. Heat flow evolution of cement pastes with different TEA dosages at w/c ratios of (a) 0.4 and (b) 1.58

favoured than in the reference paste. Dispersion could come from TEA's ability to induce repulsive depletion forces. Moreover, the addition of TEA significantly stabilised cement pastes during settling and also increased paste viscosity. This mesostructural organisation might be induced by favoured particle dispersion and an increase in the solid volume fraction due to the formation of hydrates. Lastly, the chemical reactivity of admixtured cement pastes was analysed using isothermal calorimetry and XRD. The addition of TEA significantly increased the quantity of gypsum dissolved and ettringite formed in undiluted cement pastes. At a higher w/c ratio, cement hydration was significantly less activated by TEA addition. At later ages, for both dilution rates, hydration of the calcium aluminate phase was strongly favoured, leading to an inversion of hydration peaks between calcium silicate and aluminate phases. All in all, TEA addition favours paste stabilisation, probably by dispersion and/or aggregation, and accelerates hydration of the calcium aluminate phase. A combined study of mesostructural organisation and chemical reactivity of cement pastes thus appears to be necessary in order to understand the mode of action of cement additives.

\section{Acknowledgements}

The authors thank the CIFRE convention of the French ANRT (Association Nationale de la Recherche et de la Technologie) for financing this project. Thanks also go to Philippe Gaveau 
(IGC Montpellier, France) for his help concerning the acquisition of NMR spectra.

\section{REFERENCES}

Aggoun S, Cheikh-Zouaoui M, Chikh N and Duval R (2008) Effect of some admixtures on the setting time and strength evolution of cement pastes at early ages. Construction and Building Materials 22(2): 106-110.

Aiad I, Mohammed AA and Abo-El-Enein SA (2003) Rheological properties of cement pastes admixed with some alkanolamines. Cement and Concrete Research 33(1): 9-13.

Arvaniti EC, Juenger MCG, Bernal SA et al. (2015) Determination of particle size, surface area, and shape of supplementary cementitious materials by different techniques. Materials and Structures 48(44): 3687-3701.

Autier C, Azéma N and Boustingorry P (2014) Using settling behaviour to study mesostructural organization of cement pastes and superplasticizer efficiency. Colloids and Surfaces $A$ :

Physicochemical and Engineering Aspects 450: 36-45, https://doi. org/10.1016/j.colsurfa.2014.02.050.

Berodier EJM (2015) Impact of the Supplementary Cementitious Materials on the Kinetics and Microstructural Development of Cement Hydration. PhD thesis, Ecole Polytechnique Fédérale de Lausanne, Lausanne, Switzerland.

Costoya Fernandez MM (2008) Effect of Particle Size on the Hydration Kinetics and Microstructural Development of Tricalcium Silicate. $\mathrm{PhD}$ thesis, Ecole Polytechnique Fédérale de Lausanne, Lausanne, Switzerland.

De Oliveira IR, Studart AR, Valenzuela FAO and Pandolfelli VC (2003) Setting behavior of ultra-low cement refractory castables in the presence of citrate and polymethacrylate salts. Journal of the European Ceramic Society 23(13): 2225-2235.

Elakneswaran Y, Nawa T and Kurumisawa K (2009) Zeta potential study of paste blends with slag. Cement \& Concrete Composites 31(1): 72-76.

Flatt R (2001) Polymeric dispersants in concrete. In Polymers in Particulate Systems: Properties and Applications (Hackley VA Somasundaran P and Lewis JA (eds)). CRC Press, Boca Raton, FL, USA, pp. 247-294.

Gartner E and Myers D (1993) Influence of tertiary alkanolamines on Portland cement hydration. Journal of the American Ceramic Society 76(6): 1521-1530.

Han D and Ferron RD (2016) Influence of high mixing intensity on rheology, hydration, and microstructure of fresh state cement paste. Cement and Concrete Research 84: 95-106, https://doi.org/10.1016/ j.cemconres.2016.03.004.

Han J, Wang K, Shi J and Wang Y (2015) Mechanism of triethanolamine on Portland cement hydration process and microstructure characteristics. Construction and Building Materials 93: 457-462, https://doi.org/10.1016/j.conbuildmat.2015.06.018.

Heinz D, Göbel M, Hilbig H, Urbonas L and Bujauskaite G (2010) Effect of TEA on fly ash solubility and early age strength of mortar. Cement and Concrete Research 40(3): 392-397.

Heren Z and Ölmez H (1996) The influence of ethanolamines on the hydration and mechanical properties of Portland cement. Cement and Concrete Research 26(5): 701-705.

Huang $\mathrm{H}$ and Shen X (2014) Interaction effect of triisopropanolamine and glucose on the hydration of Portland cement. Construction and Building Materials 65: 360-366, https://doi.org/10.1016/j. conbuildmat.2014.04.077.

Kim S, Hyun K, Moon JY, Clasen C and Ahn KH (2015) Depletion stabilization in nanoparticle - polymer suspensions: multi-lengthscale analysis of microstructure. Langmuir 31(6): 1892-1900.
Le Saoût G, Lécolier E, Rivereau A and Zanni H (2006) Chemical structure of cement aged at normal and elevated temperatures and pressures, part II: low permeability class G oilwell cement. Cement and Concrete Research 36(3): 428-433.

Le Saoût G, Kocaba V and Scrivener K (2011) Application of the Rietveld method to the analysis of anhydrous cement. Cement and Concrete Research 41(2): 133-148.

Levine AD, Tschobanoglous G and Asano T (1991) Size distributions of particulate contaminants in wastewater and their impact on treatability. Water Research 25(8): 911-922.

Lothenbach B and Winnefeld F (2006) Thermodynamic modelling of the hydration of Portland cement. Cement and Concrete Research 36(2): 209-226.

Menek N and Heren Z (2000) Analysis of triethanolamine in trass cement pastes by voltammetric methods. Cement and Concrete Research 30(10): 1615-1617.

Mengual O, Meunier G, Cayre I, Puech K and Snabre P (1999a) Characterisation of instability of concentrated dispersions by a new optical analyser: the Turbiscan MA 1000. Colloids and Surfaces A: Physicochemical and Engineering Aspects 152(1-2): $111-123$.

Mengual O, Meunier G, Cayre I, Puech K and Snabre P (1999b) Turbiscan MA 2000: multiple light scattering measurement for concentrated emulsion and suspension instability analysis. Talanta 50(2): 445-456.

Mikanovic N and Jolicoeur C (2008) Influence of superplasticizers on the rheology and stability of limestone and cement pastes. Cement and Concrete Research 38(7): 907-919.

Mutin J, Nachbaur L and Nkinamubanzi P (1998) Electrokinetic properties which control the coagulation of silicate cement suspensions during early age hydration. Journal of Colloid and Interface Science 268(202): 261-268.

Neubauer CM, Yang M and Jennings HM (1998) Interparticle potential and sedimentation behavior of cement suspensions: effects of admixtures. Advanced Cement Based Materials 8(1): 17-27.

Perez JP (2002) Etude de l'hydratation des Phases Constitutives d'un Ciment Portland et de la Résistance Mécanique des Pâtes Pures et Mortiers: Influence des Trialcanolamines. PhD thesis, Université de Bourgogne, Dijon, France.

Ramachandran VS (1976) Hydration of cement - role of triethanolamine. Cement and Concrete Research 6(5): 623-631.

Scrivener KL, Juilland P and Monteiro PJM (2015) Advances in understanding hydration of Portland cement. Cement and Concrete Research 78: 38-56, https://doi.org/10.1016/j.cemconres.2015.05. 025 .

Semenov AN and Shvets AA (2015) Theory of colloid depletion stabilization by unattached and adsorbed polymers. Soft Matter 11(45): 8863-8878.

Shi C, Zhang G, He T and Li Y (2016) Effects of superplasticizers on the stability and morphology of ettringite. Construction and Building Materials 112: 261-266, https://doi.org/10.1016/j.conbuildmat. 2016.02.198

Skibsted J and Jakobsen HJ (1998) Characterization of the calcium silicate and aluminate phases in anhydrous and hydrated Portland cements by $27 \mathrm{Al}$ and 29Si MAS NMR spectroscopy. In Nuclear Magnetic Resonance Spectroscopy of Cement-Based Materials (Colombet P, Zanni H, Grimmer AR and Sozzani P (eds)). Springer, Berlin, Germany, pp. 3-45.

Tritthart J and Häussler F (2003) Pore solution analysis of cement pastes and nanostructural investigations of hydrated C3S. Cement and Concrete Research 33(7): 1063-1070.

Williams DA, Saak AW and Jennings HM (1999) Influence of mixing on the rheology of fresh cement paste. Cement and Concrete Research 29(9): 1491-1496.

Xu L, Wang P and Zhang G (2012) Formation of ettringite in Portland cement/calcium aluminate cement/calcium sulfate ternary system 
hydrates at lower temperatures. Construction and Building Materials 31: 347-352, https://doi.org/10.1016/j.conbuildmat.2011 12.078

Yang S, Wang J, Cui S, Lui H and Wang X (2017) Impact of four kinds of alkanolamines on hydration of steel slag-blended cementitious materials. Construction and Building Materials 131: 655-666, https://doi.org/10.1016/j.conbuildmat.2016.09.060.

Yaphary YL, Yu Z, Lam RHW and Lau D (2017) Effect of triethanolamine on cement hydration toward initial setting time. Construction and Building Materials 141: 94-103, https://doi.org/10.1016/j. conbuildmat.2017.02.072.
Yilmaz VT, Menek N and Odabasoglu M (1993) Quantitative determination of triethanolamine in cements. Cement and Concrete Research 23(8): 603-608.

Zhang YR, Kong XM, Lu ZC et al. (2016) Influence of triethanolamine on the hydration product of portlandite in cement paste and the mechanism. Cement and Concrete Research 87: 64-76, https://doi. org/10.1016/j.cemconres.2016.05.009.

Zingg A, Holzer L, Kaech A et al. (2008) The microstructure of dispersed and non-dispersed fresh cement pastes - new insight by cryo-microscopy. Cement and Concrete Research 38(4): $522-529$ 